\title{
Polyunsaturated Fatty Acids Ameliorate Hepatic Steatosis in Obese Mice by SREBP-1 Suppression
}

\author{
Motohiro Sekiya, ${ }^{1}$ Naoya Yahagi, ${ }^{1}$ Takashi Matsuzaka, ${ }^{2}$ Yuho Najima, ${ }^{1}$ Masanori Nakakuki, ${ }^{2}$ Ryozo Nagai, ${ }^{1}$ \\ Shun Ishibashi, ${ }^{1}$ Jun-ichi Osuga, ${ }^{1}$ Nobuhiro Yamada, ${ }^{2}$ and Hitoshi Shimano ${ }^{2}$
}

Leptin-deficient $o b / o b$ mice show many characteristics of obesity, including excess peripheral adiposity as well as severe hepatic steatosis, at least in part, due to increased hepatic lipogenesis. Polyunsaturated fatty acids (PUFAs) are not only ligands for peroxisome proliferator-activated receptor (PPAR) $\alpha$ but are also negative regulators of hepatic lipogenesis, which is thought to be mediated by the repression of sterol regulatory element-binding protein (SREBP)-1. We have previously shown that the disruption of SREBP-1 in ob/ob mice decreased their liver triglyceride storage. To examine whether PUFAs could reduce hepatic triglyceride deposition, we challenged $o b / o b$ mice with dietary PUFA. It is demonstrated that PUFA markedly decreased the mature form of SREBP-1 protein and thereby reduced the expression of lipogenic genes such as fatty acid synthase (FAS) and stearoyl-CoA desaturase 1 (SCD1) in the livers of $o b / o b$ mice. Consequently, the liver triglyceride content and plasma alanine aminotransferase (ALT) levels were decreased. Furthermore, both hyperglycemia and hyperinsulinemia in $o b / o b$ mice were improved by PUFA administration, similar to the effect of PPAR $\alpha$ activators. In conclusion, PUFAs ameliorate obesity-associated symptoms, such as hepatic steatosis and insulin resistance, presumably through both down-regulation of SREBP-1 and activation of PPAR $\alpha$. (HEPATOLOGY 2003;38:1529-1539.)

$\mathrm{S}$ terol regulatory element-binding proteins (SREBPs) are members of the basic helix-loop-helix leucine zipper family of transcription factors that regulate fatty acid and cholesterol synthesis (reviewed in Brown and Goldstein ${ }^{1}$ ). Unlike other members of the family, SREBPs are synthesized as precursors bound to the endoplasmic reticulum and nuclear envelope and are released from the membrane into the nucleus as mature proteins by cleavage processes. To date, 3 isoforms of SREBP, -1 a, $-1 \mathrm{c}$, and -2 , have been identified and characterized. The predominant SREBP-1 isoform in liver and adipose tissue is SREBP-1c. Whereas SREBP-2 plays a crucial role in regulation of cholesterol synthesis, SREBP-1c controls

Abbreviations: SREBP, sterol regulatory element-binding protein; $F A S$, fatty acid synthase; SCD, stearoyl-CoA desaturase; PUFA, polyunsaturated fatty acid(s); $A C L$, ATP citrate lyase; EPA, eicosapentaenoic acid; DHA, docosahexaenoic acid; PPAR, peroxisome proliferator-activated receptor.

From the ${ }^{1}$ Department of Internal Medicine, Tokyo University Graduate School of Medicine, Tokyo, and ${ }^{2}$ Department of Internal Medicine, Institute of Clinical Medicine, University of Tsukuba, Ibaraki, Japan.

Received April 28, 2003; accepted September 5, 2003.

Address reprint requests to: Hitoshi Shimano, M.D., Ph.D., Department of Internal Medicine, Institute of Clinical Medicine, University of Tsukuba, 1-1-1 Tennodai, Tsukuba, Ibaraki305-8575, Japan.E-mail: shimano-tky@umin.ac.jp; fax: (81) 298-63-2081.

Copyright () 2003 by the American Association for the Study of Liver Diseases. 0270-9139/03/3806-0026\$30.00/0

doi:10.1016/j.hep.2003.09.028 the transcription and expression of lipogenic enzymes such as fatty acid synthase (FAS) and stearoyl-CoA desaturase 1 (SCD1) (reviewed in Shimano ${ }^{2}$ and Horton et al. ${ }^{3}$ ). It is remarkable that SREBP-1c regulates not only the synthetic rate of triglycerides but also the amount of their storage in the liver. ${ }^{4,5}$ Thus, SREBP-1 has been revealed to be a promising target for hepatic steatosis (fatty livers) from a therapeutic point of view.

The leptin-deficient ob/ob mouse model of obesity exhibits severe obesity and obesity-related symptoms, including hepatic steatosis and insulin resistance (reviewed in Bray and York $^{6}$ ). The livers of $o b / o b$ mice have an increase in triglyceride content, probably because of the increased lipogenesis paralleled by elevated messenger RNA (mRNA) expression and enzymatic activity of several lipogenic enzymes such as FAS and SCD 1.6,7 Recently, it has been reported that both SREBP-1c mRNA and its active nuclear protein are increased in ob/ob mouse livers. ${ }^{8}$ Furthermore, we have demonstrated in a previous report ${ }^{5}$ that the disruption of the SREBP-1 gene in $o b / o b$ mice leads to marked amelioration of hepatic steatosis.

Dietary polyunsaturated fatty acids (PUFAs) of the $n-6$ and $n-3$ families are well established as negative regulators of hepatic lipogenesis (reviewed in Clark and Jump ${ }^{9}$ ). Recently, others and we have shown that the suppressive 
effects of PUFA on lipogenic enzymes are mediated by their reduction of mature SREBP-1 protein in the liver. ${ }^{10-13}$ The primary mechanism by which PUFAs suppress SREBP-1 is presumably by cleaving the precursor protein as well as by the reduction of both transcription rate and mRNA stability. ${ }^{14,15}$ Interestingly, PUFAs selectively decrease SREBP-1, not affecting SREBP-2.

Considering these findings, we hypothesized that PUFA would be effective for the treatment of hepatic steatosis. To test this, we examined the effects of PUFA on hepatic steatosis in the oblob mouse. We show that, in oblob mice, PUFAs ameliorate hepatic steatosis through a reduction of mature SREBP-1 protein. In addition, the administration of PUFA resulted in marked improvement of insulin resistance.

\section{Materials and Methods}

Materials. Triolein (99\% grade) and fenofibrate were purchased from Wako Pure Chemicals (Tokyo, Japan) and Sigma (St. Louis, MO), respectively. Eicosapentaenoic acid (EPA) ethyl ester (95\% grade) was provided from Mochida pharmaceutical (Tokyo, Japan) and pioglitazone (100.0\% pure) from Takeda pharmaceutical (Tokyo, Japan). Fish oils (extracted from tuna; containing 24.8\% docosahexaenoic acid [DHA] and 8.1\% EPA) were provided from NOF (Tokyo, Japan). Standard laboratory chow (composed of $60 \%$ carbohydrate, $13 \%$ fat, and $27 \%$ protein on a caloric basis; Oriental MF, Oriental Yeast, Tokyo, Japan), high-carbohydrate, fat-free diet (70\% sucrose; $10 \%$ starch; and $20 \%$ casein supplemented with methionine, vitamins, and minerals), and high-protein, fat-free diet (100\% casein and no carbohydrate supplemented with methionine, vitamins, and minerals) were obtained from Oriental Yeast (Tokyo, Japan).

Animals. Heterozygous Lep ${ }^{\text {ob/+ }}$ C57BL/6J mice were purchased from Jackson Laboratories (Bar Harbor, ME). Eight-week-old wild-type and $o b / o b$ male littermates were used in all experiments. Genotypes at the leptin locus were determined by a PCR-based, restricted fragment length polymorphism analysis as described previously. ${ }^{5}$ Mice were housed in a temperature-controlled environment with a 12-hour light/dark cycle (light: 10:00 AM to 10:00 PM) and given free access to water and a standard chow diet for the 1-week adaptation period. Each group of 4 animals (kept all together in 1 cage) was fed a control high-carbohydrate, fat-free chow or that supplemented with either 15\% triolein, 15\% triolein plus 5\% EPA ethyl ester (approximately $5 \mathrm{~g} / \mathrm{kg} / \mathrm{d}$ ), 20\% fish oil, $0.125 \%$ fenofibrate, or $0.05 \%$ pioglitazone for 7 days. We determined this duration based on the preliminary data that 7-day administration of fish oil decreased the serum ala- nine aminotransferase (ALT) level to the same extent as was observed at the 14th day, whereas 3-day feeding was not sufficient. After collecting blood samples from the retroorbital sinus, animals were killed by cervical dislocation in an early phase of the light cycle in a nonfasted state. SREBP-1c transgenic mice over-expressing amino acids 1-436 of human SREBP-1c under control of the rat PEPCK promoter (TgSREBP1) were made as previously described. ${ }^{4} \mathrm{~A}$ line homozygous for the transgene was established and used. The diets used for TgSREBP1 mice experiments were based on the high-protein, fat-free diet to maximize the transgene expression and mixed with $15 \%$ triolein, $15 \%$ triolein plus 5\% EPA ethyl ester, or $20 \%$ fish oil. All experiments were repeated at least twice, and the data from a representative experiment were shown.

Blood Chemistries and Liver Lipid Analyses. Enzymatic assay kits were used for the determination of cholesterol (Determiner TC: cholesterol oxidase method; Kyowa Medex, Tokyo, Japan), triglycerides (TG LH: lipoprotein lipase method; Wako Pure Chemicals, Tokyo, Japan), nonesterified fatty acids (NEFA C: acyl-CoA oxidase method; Wako Pure Chemicals) and ALT (transaminase C- II: POP TOOS method; Wako Pure Chemicals). Plasma glucose was measured by ANTSENSE II (Bayer Medical, Tokyo, Japan) based on immobilized glucose oxidase membrane/hydrogen peroxide electrode method. Plasma insulin was determined by the mouse insulin ELISA kit (Wako Pure Chemicals). The content of cholesterol and triglycerides in liver was measured as described previously. ${ }^{16}$

RNA Isolation and Northern Blotting. Total RNA from liver and epididymal fat pad was isolated with Trizol Reagent (Invitrogen), and $10 \mu \mathrm{g}$ RNA samples were equally pooled from 4 mice of each group and $(2.5 \mu \mathrm{g}$ RNA for each mouse) were run on a $1 \%$ agarose gel containing formaldehyde and transferred to a nylon membrane. The cDNA probes used were cloned as previously described. ${ }^{17}$ The probes were labeled with $\left[\alpha-{ }^{32} \mathrm{P}\right] \mathrm{dCTP}$ using Megaprime DNA Labelling System kit (Amersham Biosciences). The membranes were hybridized with the radiolabeled probe in Rapid-hyb Buffer (Amersham Biosciences) at $65^{\circ} \mathrm{C}$. The membranes were washed 3 times (10 minutes each) in $0.1 \mathrm{X} \mathrm{SSC}, 0.1 \%$ SDS at $65^{\circ} \mathrm{C}$. Blots were exposed to Kodak XAR-5 film and the BAS imaging plate for BAS2000 BIO IMAGING ANALYZER (Fuji Photo Film, Tokyo, Japan). The quantification results obtained with BAS2000 system were normalized to the signal generated from 36B4 (acidic ribosomal phosphoprotein P0) mRNA.

RNase Protection Assay. RNase protection assay was performed as described previously. ${ }^{18}$ Briefly, after linear- 
A
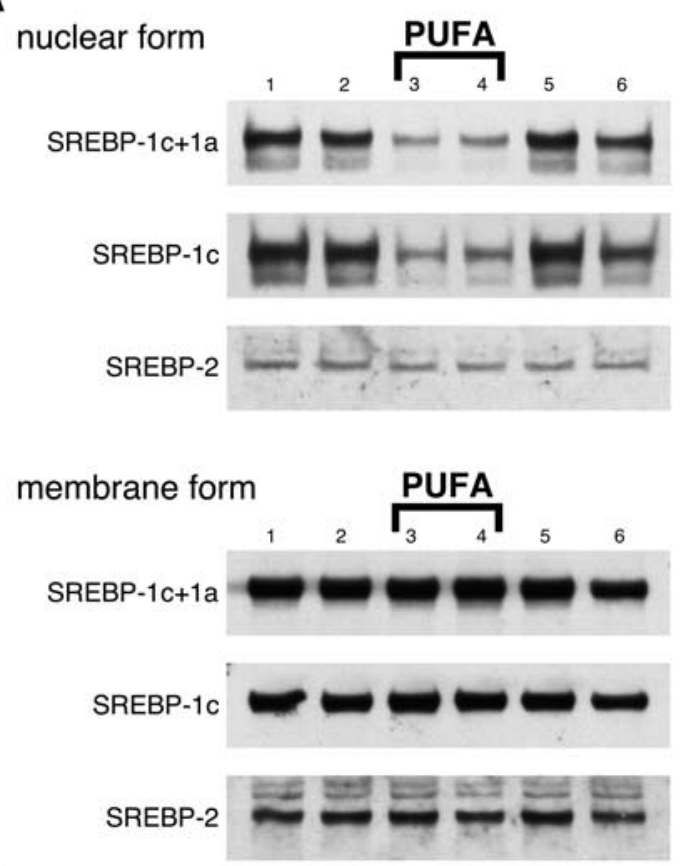

B

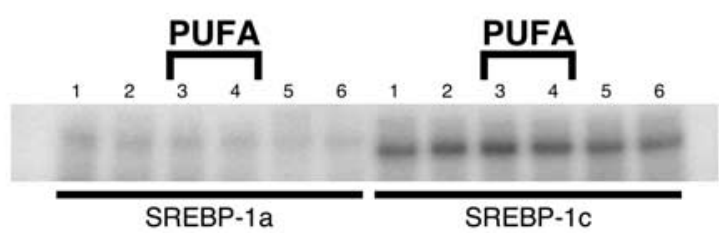

Fig. 1. PUFAs reduce mature SREBP-1 in the nuclei from $o b / o b$ mice livers. (A) Immunoblot analysis of SREBP-1 and -2 in nuclear extracts and membrane fractions from livers of $o b / o b$ mice are shown. Mice (4 male $o b / o b$ mice for each group) were fed a high-carbohydrate fat-free diet (lane 1) or a high-carbohydrate diet supplemented with $15 \%$ triolein (lane 2), 5\% EPA ethyl ester plus 15\% triolein (lane 3), 20\% fish oil (lane 4), $0.125 \%$ fenofibrate (lane 5), or $0.05 \%$ pioglitazone (lane 6) for 7 days before being killed in a nonfasted state. Aliquots of nuclear extracts $(20 \mu \mathrm{g}$ protein) and membrane proteins $(30 \mu \mathrm{g})$ from pooled livers of each group were subjected to immunoblot analysis. The primary antibodies used were polyclonal anti-mouse SREBP-1 (1c plus 1a and 1c-specific) and -2. (B) Quantification of SREBP-1a and -1c by RNase protection assay are shown. Lanes are the same as above. The protected fragments for SREBP-1a and -1c contain the same number of cytidine phosphates (32 cytidines), so the intensity of each band was proportional to the amount of each isoform in the samples. Series of experiments were performed twice for the same number of animals, and the data from a representative experiment are shown.

ization of the template plasmid DNA with Hind III, antisense RNA probes for SREBP-1a and -1c were transcribed with $\left[\alpha-{ }^{32} \mathrm{P}\right] \mathrm{CTP}$ using bacteriophage T7 RNA polymerase (MAXIscript in vitro transcription kit; Ambion) and purified by electrophoresis on 5\% polyacrylamide gel. Then, aliquots of probes and total RNA $(10 \mu \mathrm{g})$ pooled within each group $(2.5 \mu \mathrm{g}$ RNA for each mouse) were mixed and subjected to the RNase protection assay using HybSpeed RPA kit (Ambion). After digestion with RNase $\mathrm{A} / \mathrm{T} 1$, protected fragments were separated on $8 \mathrm{~mol} / \mathrm{L}$ urea $/ 10 \%$ polyacrylamide gels. The protected fragments for SREBP-1a and - $1 \mathrm{c}$ contained the same number of cytidine phosphates (32 cytidines), so the intensity of each band was proportional to the amount of each isoform in the samples. The gels were subjected to Kodak XAR-5 film and the BAS2000 BIO IMAGING ANALYZER (Fuji Photo Film, Tokyo, Japan).

Immunoblotting of SREBP Proteins. Nuclear extracts and membrane fractions from mice livers were prepared as previously described. ${ }^{19}$ Aliquots of nuclear (20 $\mu \mathrm{g})$ and membrane $(30 \mu \mathrm{g})$ proteins were subjected to SDS/PAGE. Immunoblot analysis was performed using the ECL Western Blotting Detection System kit (Amersham Biosciences) and exposed to Kodak XAR-5 film. The primary antibodies (rabbit polyclonal; No. 931 for mouse SREBP-1a and -1c, No. 772 for SREBP-1c, which

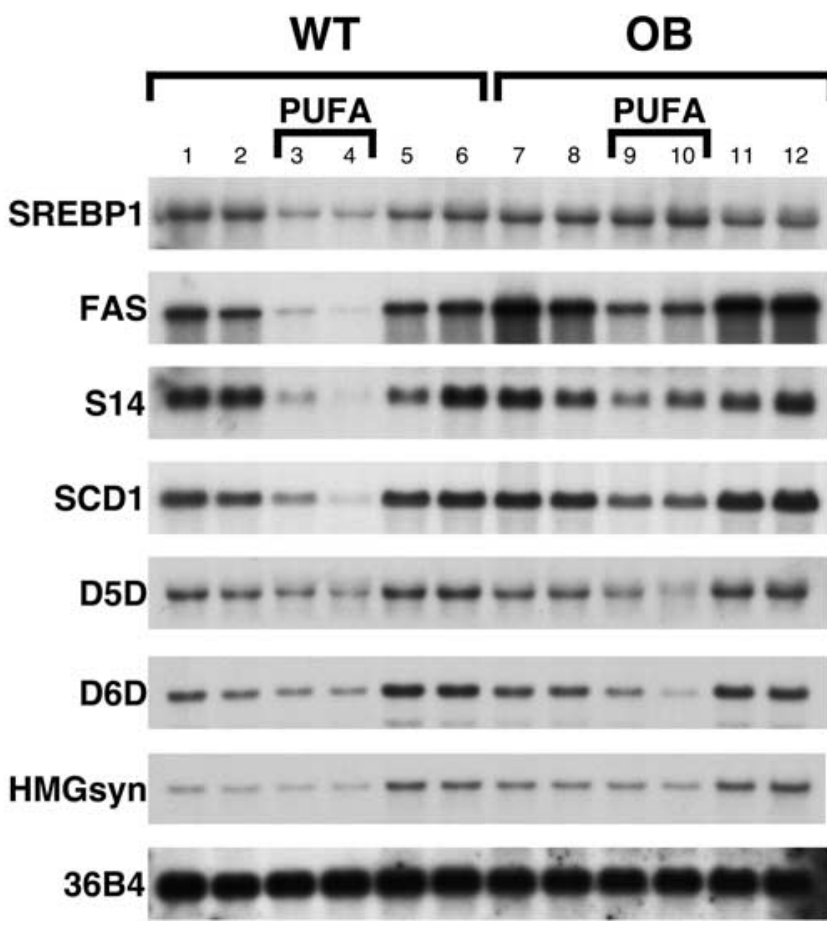

Fig. 2. PUFAs repress lipogenic enzymes in liver. Northern blot analysis from mice livers. Wild-type (lanes 1-6) and ob/ob (lanes 7-12) mice ( 4 mice for each group) were fed the indicated diet for 7 days and killed in a nonfasted state. Diets were as follows: lanes $\mathbf{1}$ and $\mathbf{7}$, a highcarbohydrate, fat-free diet; lanes $\mathbf{2}$ and $\mathbf{8}$, a high-carbohydrate diet with 15\% triolein (C18:1 n-9); lanes 3 and 9, 5\% EPA ethyl ester (C20:5 n-3) plus 15\% triolein (C18:1 n-9); lanes 4 and 10, 20\% tuna fish oil; lanes 5 and 11, 0.125\% fenofibrate, a PPAR $\alpha$ agonist; and lanes 6 and 12, $0.05 \%$ pioglitazone, a PPAR $\gamma$ agonist. Total RNA $(10 \mu \mathrm{g})$ pooled equally from 4 mice was subjected to Northern blotting, followed by hybridization with the indicated CDNA probes. SREBP1, sterol regulatory elementbinding protein-1; FAS, fatty acid synthase; S14, Spot 14; SCD1, stearoyl-CoA desaturase 1; D5D, $\Delta 5$-desaturase; D6D, $\Delta 6$-desaturase; HMGsyn, hydroxymethylglutaryl-CoA synthase. A cDNA probe for 36B4 (acidic ribosomal phosphoprotein P0) was used to confirm equal loading. Series of experiments were performed twice for the same number of animals, and the data from a representative experiment are shown. 

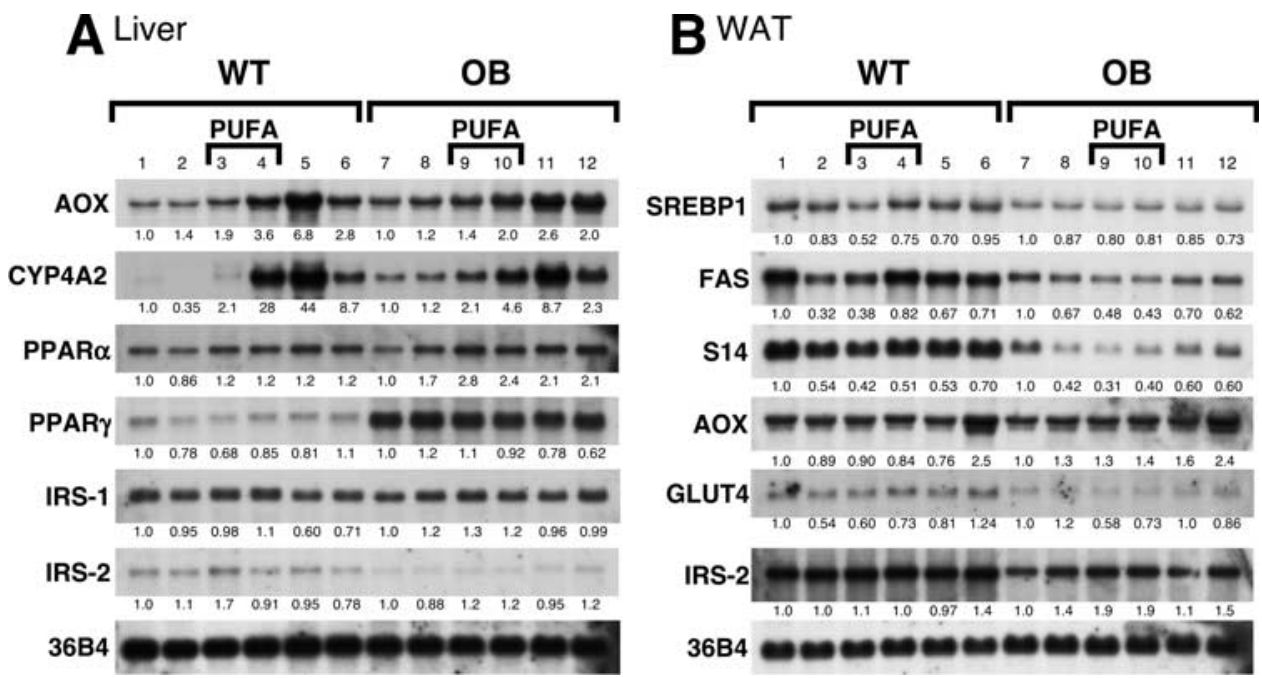

Fig. 3. PUFAs induce PPAR $\alpha$-target genes. (A) Northern blot analysis from mice livers and (B) adipose tissue. Wild-type (lanes 1-6) and $o b / o b$ (lanes 7-12) mice (4 mice for each group) were fed the indicated diet for 7 days and killed in a nonfasted state. Diets were as follows: lanes 1 and 7, a high-carbohydrate, fat-free diet; lanes $\mathbf{2}$ and $\mathbf{8}$, a high-carbohydrate diet with 15\% triolein (C18:1 n-9); lanes $\mathbf{3}$ and $\mathbf{9}, 5 \%$ EPA ethyl ester (C20:5 n-3) plus 15\% triolein (C18:1 n-9); lanes 4 and 10, 20\% tuna fish oil; lanes $\mathbf{5}$ and 11, 0.125\% fenofibrate, a PPAR $\alpha$ agonist; and lanes 6 and 12, 0.05\% pioglitazone, a PPAR $\gamma$ agonist. Total RNA $(10 \mu \mathrm{g})$, pooled equally from four mice, was subjected to Northern blotting, followed by hybridization with the indicated cDNA probes. AOX, acyl-CoA oxidase; CYP4A2, cytochrome P450 4A2; PPAR, peroxisome proliferator-activated receptor; IRS, insulin receptor substrate; SREBP1, sterol regulatory element-binding protein-1; FAS, fatty acid synthase; S14, Spot 14; GLUT4, glucose transporter 4. A cDNA probe for 36B4 (acidic ribosomal phosphoprotein P0) was used to confirm equal loading. The quantification results were obtained with BAS2000 system and normalized to the signal generated from 36B4 (acidic ribosomal phosphoprotein P0) mRNA, and the fold-changes against control were displayed below each blot. Series of experiments were performed twice for the same number of animals, and the data from a representative experiment are shown.

does not bind to SREBP-1a, and No. 528 for SREBP-2) were as previously described. ${ }^{17,20}$

Fatty Acid Composition of Liver. An aliquot $(0.1 \mathrm{~g})$ of liver samples snap-frozen by liquid nitrogen was homogenized in $1 \mathrm{~mL}$ of normal saline. The fatty acid composition was measured by gas chromatography at BioMedical Laboratories (Tokyo, Japan). ${ }^{21}$ Briefly, total lipids in liver homogenates were extracted according to the Folch's procedure, ${ }^{22}$ followed by transesterification of fatty acids with boron trifluoride-methanol at $100^{\circ} \mathrm{C}$ for 90 minutes. The methylated fatty acids were then extracted with hexane and analyzed using GC-17A gas chromatograph (Shimadzu Corporation, Kyoto, Japan) and BPX70 capillary column $(0.25 \mathrm{~mm}$ ID $\times 30 \mathrm{~m}$, SGE International Ltd., Melbourne, Australia).

Statistical Analysis. Data are presented as means \pm SE. All data were analyzed by 2 -tailed Student's $t$ test against control. Differences were considered statistically significant at $P<.05$.

\section{Results}

Effects of PUFA on the Mature Form of SREBP-1 in ob/ob Mice Livers. In wild-type mice, PUFAs have been shown to decrease the mature form of SREBP-1 in the liver. ${ }^{10-13}$ To examine effects of PUFA on SREBP-1 in leptin-deficient $o b / o b$ mice livers in which SREBP-1 is dysregulated, they were fed a high-carbohydrate diet supplemented with PUFA (EPA or tuna fish oil enriched in DHA) or control diet for 7 days. As expected, immunoblot analysis of liver nuclear extracts showed that $o b / o b$ mice fed a diet with EPA or fish oil for 7 days had $\sim 3$-fold lower SREBP-1 mature protein than those fed the control diet (high-carbohydrate without fat) (Fig. 1A). In contrast, monounsaturated fatty acids (oleate) did not reduce mature SREBP-1.

To clarify the mechanism by which PUFAs down-regulate mature SREBP-1 protein, the amounts of SREBP-1 (both precursor and mature forms in the membrane and nuclear extracts, respectively; Fig. 1A) as well as SREBP-1 mRNA levels (Fig. 1B) were compared between control and PUFA (EPA or fish oil)-fed ob/ob mice. In contrast to the mature protein, which was profoundly decreased by PUFA feeding, no reduction was observed in either mRNA or membrane-bound precursor protein levels. This indicates that PUFAs regulate the abundance of mature SREBP-1 protein mainly at a posttranslational level, presumably through cleavage processes.

RNase protection assay with probes that can discriminate SREBP-1a and -1c (Fig. 1B) also demonstrated that the isoform pattern of SREBP-1 is SREBP-1c-dominant 
Fig. 4. PUFAs ameliorate hepatic steatosis of $o b / o b$ mice. (A) liver triglyceride (TG) and total cholesterol (TC) content per body weight in wild-type (lanes 1-6) and ob/ob mice (lanes 7-12). Diets are as follows: lanes 1 and 7, a high-carbohydrate, fat-free diet; lanes $\mathbf{2}$ and $\mathbf{8}$, $15 \%$ triolein (C18:1 n-9); lanes 3 and 9, 5\% EPA ethyl ester (C20:5 $\mathrm{n}-3)$ plus $15 \%$ triolein (C18:1 n-9); lanes 4 and 10, 20\% tuna fish oil; lanes 5 and 11, 0.125\% fenofibrate, a PPAR $\alpha$ agonist; and lanes 6 and 12, 0.05\% pioglitazone, a PPAR $\gamma$ agonist. Each group consisted of 4 male mice except for lanes 7 and $9(n=8)$. (B) Plasma ALT levels. Lanes are the same as above. (C) Liver lipid content of wildtype and SREBP-1 transgenic mice. Lanes are as follows: lane 1, wildtype mice fed with a high-carbohydrate, fat-free diet; lane 2, SREBP-1 transgenic (TgSREBP1) mice fed with a high-protein, fat-free diet; lane 3, TgSREBP1 mice fed with 5\% EPA ethyl ester plus 15\% triolein; lane 4, TgSREBP1 mice fed with $20 \%$ fish oil. Bars $=$ SE. $*$ Denotes significance vs. control (lane 1 or $\mathbf{7}$ ) at $P<.05$ (Student's $t$ test). Series of experiments were performed 3 times for the same number of animals, and the data from a representative experiment are shown.

\section{A Liver lipid / BW}
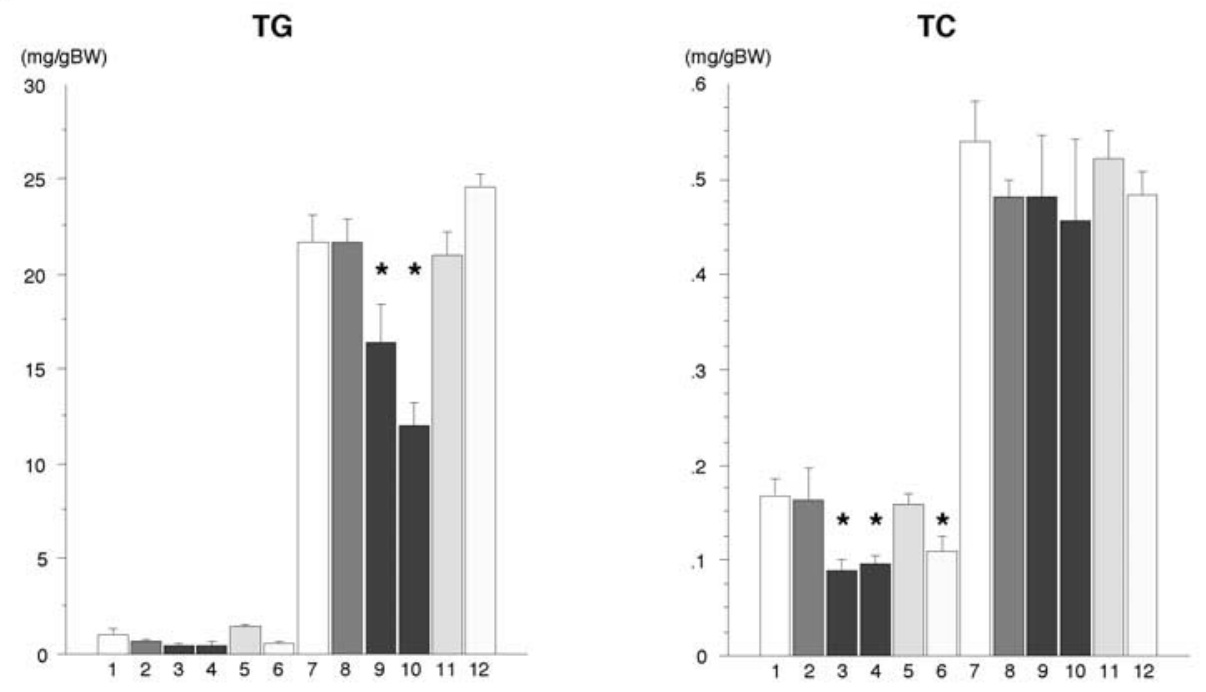

\section{B Plasma ALT}

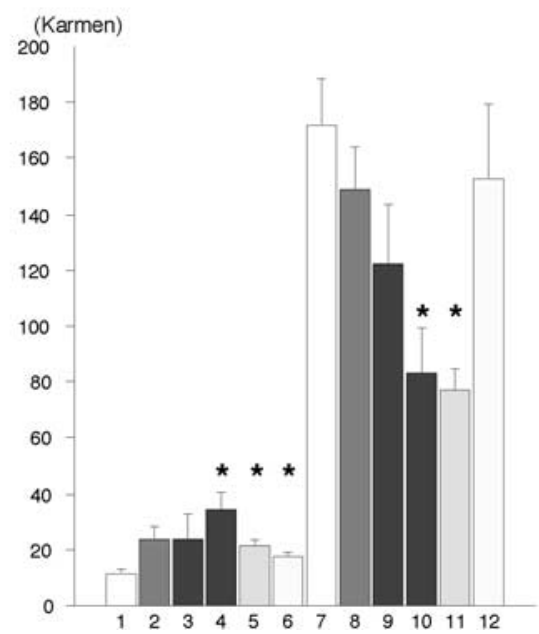

C TgSREBP1 liver lipid / BW

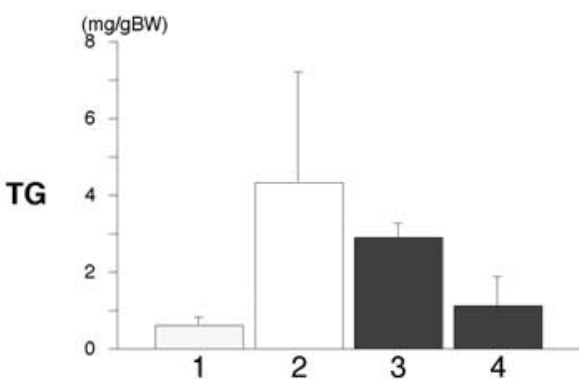

in ob/ob mice livers, which is the same as in wildtype mice. ${ }^{18}$ This was further supported by Western blot analysis with an SREBP-1c-specific antibody (Fig. 1A).

Fenofibrate and pioglitazone, peroxisome proliferatoractivated receptor (PPAR) $\alpha$ and $\gamma$ agonists, respectively, were also tested, but neither altered mature SREBP-1 levels. The amount of mature SREBP-2 protein did not change with any of these diets.

Suppression of Lipogenic Gene Expressions by PUFA. We compared the mRNA levels of genes encoding lipogenic enzymes in the livers of mice fed diets with or without PUFA (EPA or fish oil) for 7 days as measured by Northern blot analysis. Consistent with previous reports, dietary PUFA suppressed hepatic expression of SREBP-1-target lipogenic genes such as FAS and SCD1 in wild-type mice (Fig. 2). Similar suppression of these genes was also observed in livers from oblob mice fed the PUFA diets. Meanwhile, suppression of these lipogenic genes was not observed in white adipose tissue from either group (Fig. 3).

The $\Delta 5$ - and $\Delta 6$-desaturases, key players in the production of EPA and DHA, have been reported to be suppressed by PUFA.23,24 We previously reported that they are dually regulated by SREBP- 1 and PPAR $\alpha$ and suppressed by PUFA in wild-type mouse liver. ${ }^{25}$ However, because PUFAs suppress SREBP-1 and at the same time activate PPAR $\alpha$, it is unclear whether PUFAs decrease or increase these desatureases as an overall effect in various nutritional situations. In the current study, it was revealed that, in both wild-type and oblob mice, PUFA diets reduced the expression of these enzymes, whereas PPAR $\alpha$ activation by fenofibrate consistently increased their expression. 
Table 1. Representative Profile of Wild-Type and ob/ob Mice Used for the Experiment

\begin{tabular}{|c|c|c|c|c|c|c|c|}
\hline & & 1 & 2 & 3 & 4 & 5 & 6 \\
\hline \multicolumn{8}{|l|}{ Wild-type } \\
\hline \multirow[t]{2}{*}{ Body weight (g) } & Pre & $26.4 \pm 1.9$ & $26.4 \pm 1.9$ & $26.4 \pm 1.6$ & $26.5 \pm 1.5$ & $26.4 \pm 1.3$ & $26.4 \pm 1.2$ \\
\hline & At sacrifice & $26.3 \pm 2.1$ & $26.8 \pm 1.8$ & $27.0 \pm 1.5$ & $25.1 \pm 0.7$ & $25.5 \pm 1.1$ & $26.8 \pm 1.0$ \\
\hline Liver weight (g) & & $1.35 \pm 0.17$ & $1.43 \pm 0.13$ & $1.25 \pm 0.09$ & $1.40 \pm 0.10$ & $2.33 \pm 0.10^{*}$ & $1.53 \pm 0.05$ \\
\hline WAT weight (g) & & $0.28 \pm 0.08$ & $0.33 \pm 0.05$ & $0.53 \pm 0.16$ & $0.28 \pm 0.05$ & $0.20 \pm 0.00$ & $0.40 \pm 0.07$ \\
\hline \multirow{2}{*}{ Plasma data } & $\mathrm{TC}(\mathrm{mg} / \mathrm{dL})$ & $72.5 \pm 16.0$ & $121.9 \pm 5.5^{*}$ & $61.2 \pm 9.3$ & $57.2 \pm 8.3$ & $109.1 \pm 7.4$ & $106.0 \pm 5.9$ \\
\hline & $\mathrm{TG}(\mathrm{mg} / \mathrm{dL})$ & $64.2 \pm 10.2$ & $88.5 \pm 11.1$ & $55.1 \pm 2.8$ & $46.9 \pm 2.8$ & $66.7 \pm 3.8$ & $46.4 \pm 2.2$ \\
\hline \multicolumn{8}{|l|}{$a b / o b$} \\
\hline \multirow[t]{2}{*}{ Body weight (g) } & Pre & $50.5 \pm 2.5$ & $50.3 \pm 2.4$ & $50.6 \pm 2.1$ & $50.4 \pm 2.0$ & $50.1 \pm 1.9$ & $50.4 \pm 1.6$ \\
\hline & At sacrifice & $52.3 \pm 2.1$ & $53.6 \pm 2.5$ & $51.8 \pm 2.4$ & $51.8 \pm 2.0$ & $51.3 \pm 1.7$ & $54.1 \pm 1.8$ \\
\hline Liver weight (g) & & $6.12 \pm 0.31$ & $5.50 \pm 0.20$ & $4.58 \pm 0.40^{*}$ & $4.60 \pm 0.31^{*}$ & $5.35 \pm 0.15$ & $5.54 \pm 0.32$ \\
\hline WAT weight (g) & & $3.20 \pm 0.31$ & $3.30 \pm 0.11$ & $3.25 \pm 0.41$ & $3.62 \pm 0.13$ & $3.48 \pm 0.15$ & $3.63 \pm 0.16$ \\
\hline \multirow[t]{2}{*}{ Plasma data } & $\mathrm{TC}(\mathrm{mg} / \mathrm{dL})$ & $265.1 \pm 28.0$ & $284.5 \pm 10.3$ & $229.6 \pm 8.0$ & $330.6 \pm 24.4$ & $267.1 \pm 13.4$ & $191.5 \pm 18.5$ \\
\hline & $\mathrm{TG}(\mathrm{mg} / \mathrm{dL})$ & $115.9 \pm 11.8$ & $145.6 \pm 26.8$ & $79.6 \pm 0.6 *$ & $147.0 \pm 25.7$ & $79.6 \pm 4.0^{*}$ & $69.2 \pm 10.0 *$ \\
\hline
\end{tabular}

NOTE. Diets are as follows: 1, a high-carbohydrate fat-free diet; 2, a high-carbohydrate diet with 15\% triolein (C18:1 n-9); 3, 5\% EPA ethyl ester (C20:5 n-3) plus $15 \%$ triolein (C18:1 n-9); 4, 20\% tuna fish oil; 5, 0.125\% fenofibrate, a PPAR $\alpha$ agonist; $6,0.05 \%$ pioglitazone, a PPAR $\gamma$ agonist. Each value is mean \pm SE. Abbreviations: TC, total cholesterol; TG, triglycerides.

*Significance vs. control at $P<.05$ by Student's $t$ test.

In contrast, these lipids did not affect genes involved in cholesterol synthesis, such as hydroxymethylglutaryl (HMG)-CoA synthase, that are mainly regulated by SREBP-2 (Fig. 3). These results are consistent with the data shown in Fig. 1 in which PUFA did not affect the amount of mature SREBP-2.

Effects on PPAR $\alpha$-Regulated Genes. It is well known that PUFAs are ligands for PPAR $\alpha,,^{26,27}$ and some biologic effects of PUFA such as stimulation of peroxisomal and microsomal fatty acid oxidation are mediated by PPAR $\alpha .{ }^{28}$ Therefore, we assessed PUFA effects on the hepatic PPAR $\alpha$ pathway. As expected, mRNA levels of $\operatorname{PPAR} \alpha$-target genes such as PPAR $\alpha$ itself, acyl-CoA oxidase (AOX), and cytochrome P-450 4A2 (CYP4A2) were induced by PUFA (Fig. 3). In particular, fish oil (tuna, rich in DHA) had more potent effects than EPA on $\operatorname{PPAR} \alpha$-mediated pathways in both wild-type and $o b / o b$ mice.

Effects of PUFA on Liver Lipid Content. To determine whether the effects of PUFA reduced hepatic steatosis in $o b / o b$ mice, liver triglyceride content was measured (Fig. 4). In both wild-type and ob/ob mice, PUFA (EPA and fish oil) significantly $(P<.05)$ decreased hepatic triglyceride content per body weight. During the feeding period, mean body weights were not different among each group (Table 1), suggesting that the decrease in hepatic triglycerides was not due to reduced food intake.

Reduction of ALT by PUFA. ALT is a well-known marker for evaluation of liver injury and is elevated in animals with hepatic steatosis, including $o b / o b$ mice. We determined plasma ALT levels by enzymatic assay. Although there were no differences among each dietary group in wild-type mice, PUFA (EPA or fish oil) lowered the elevated ALT levels in $o b / o b$ mice (Fig. 4). These data are consistent with our finding that PUFA ameliorated hepatic steatosis.

Effects of PUFA on Triglyceride Content in TgSREBP1 Mice Livers. To investigate whether the reduction of triglyceride in liver can be ascribed to the decrease in mature SREBP-1, we examined a transgenic mouse model, which forcibly expresses a mature form of SREBP-1 protein in the liver (TgSREBP1). Consistent with a previous report, ${ }^{10}$ dietary PUFA did not decrease the mature SREBP-1 protein or the mRNA levels of lipogenic genes in the liver of TgSREBP1 mice (data not shown). Accordingly, the triglyceride content of EPA-fed mice was almost equal to mice fed the control diet (Fig. 4). Intriguingly, the fish oil administration still caused a remarkable reduction in the triglyceride content elevated by the over-expressed SREBP-1. These data suggest that fish oil has some additional effects beyond those mediated by SREBP-1.

Effects on Fatty Acid Composition in Liver. We measured the composition of fatty acids in liver total lipids by gas chromatography (Table 2, Fig. 5). The fatty acids that can be synthesized de novo by lipogenic enzymes such as palmitate (C16:0), palmitoleate (C16:1 n-7), and oleate (C18:1 n-9) were reduced by PUFA. Because these fatty acids dominate liver lipids, this resulted in an overall reduction in the total content of fatty acids in PUFA-fed mice. In the animals fed fish oil, EPA (C20:5 n-3) and DHA (C22:6 n-3) were abundantly distributed in the liver in both wild-type and $o b / o b$ mice. However, mice given EPA showed similarly low levels of DHA compared with control animals, despite the availability of EPA for metabolism to DHA by desaturation and elongation.

PUFA Effects on Insulin Resistance. To evaluate insulin sensitivity, we also examined some markers of glu- 
Table 2. Fatty Acid Composition in the Liver

\begin{tabular}{|c|c|c|c|c|c|c|}
\hline & 1 & 2 & 3 & 4 & 5 & 6 \\
\hline \multicolumn{7}{|c|}{ Wild-type ( $\mu \mathrm{g} / \mathrm{g}$ body weight) } \\
\hline $\mathrm{C} 12: 0$ & $0.22 \pm 0.22$ & $0.00 \pm 0.00$ & $0.00 \pm 0.00$ & $0.34 \pm 0.34$ & $0.00 \pm 0.00$ & $0.00 \pm 0.00$ \\
\hline C14:0 & $6.88 \pm 0.64$ & $4.93 \pm 0.19 *$ & $2.94 \pm 4.58^{*}$ & $3.54 \pm 0.73^{*}$ & $9.40 \pm 1.02$ & $4.84 \pm 0.22 *$ \\
\hline C14:1 n-5 & $0.00 \pm 0.00$ & $0.00 \pm 0.00$ & $0.00 \pm 0.00$ & $0.00 \pm 0.00$ & $0.00 \pm 0.00$ & $0.00 \pm 0.00$ \\
\hline C16:0 & $327.2 \pm 24.0$ & $342.6 \pm 23.4$ & $251.9 \pm 15.5^{*}$ & $394.9 \pm 13.3^{*}$ & $1084.0 \pm 96.0 *$ & $431.8 \pm 30.8 *$ \\
\hline C16:1 n-7 & $77.2 \pm 12.8$ & $51.7 \pm 3.4$ & $20.1 \pm 2.8^{*}$ & $20.9 \pm 3.3^{*}$ & $248.0 \pm 30.7^{*}$ & $97.5 \pm 8.3$ \\
\hline $\mathrm{C} 18: 0$ & $106.6 \pm 13.4$ & $125.1 \pm 11.3$ & $118.5 \pm 5.8$ & $167.1 \pm 10.2 *$ & $165.6 \pm 19.5^{*}$ & $118.8 \pm 6.7$ \\
\hline C18:1 n-9 & $475.5 \pm 25.0$ & $499.7 \pm 19.2$ & $286.6 \pm 43.9 *$ & $175.4 \pm 52.6^{*}$ & $975.8 \pm 106.9 *$ & $481.9 \pm 43.3$ \\
\hline C18:2 n-6 & $114.5 \pm 32.2$ & $113.0 \pm 17.0$ & $93.7 \pm 16.1$ & $156.8 \pm 53.0$ & $254.0 \pm 19.7^{*}$ & $64.4 \pm 4.4$ \\
\hline C18:3 n-6 & $2.14 \pm 1.12$ & $1.62 \pm 0.56$ & $0.36 \pm 0.36$ & $1.33 \pm 0.89$ & $5.69 \pm 0.73^{*}$ & $0.83 \pm 0.48$ \\
\hline C18:3 n-3 & $0.52 \pm 0.52$ & $0.44 \pm 0.44$ & $2.42 \pm 0.45^{*}$ & $3.54 \pm 1.16$ & $0.59 \pm 0.59$ & $0.00 \pm 0.00$ \\
\hline $\mathrm{C} 20: 0$ & $2.38 \pm 0.25$ & $3.00 \pm 0.03^{*}$ & $2.75 \pm 0.26$ & $3.61 \pm 0.13^{*}$ & $3.09 \pm 0.31$ & $2.00 \pm 0.09$ \\
\hline C20:1 n-9 & $19.23 \pm 1.33$ & $19.35 \pm 0.59$ & $8.01 \pm 1.36^{*}$ & $7.10 \pm 3.02 *$ & $20.14 \pm 2.57$ & $14.78 \pm 1.70$ \\
\hline C20:2 n-6 & $3.58 \pm 1.06$ & $3.14 \pm 0.60$ & $1.13 \pm 0.40$ & $2.13 \pm 0.92$ & $5.24 \pm 0.40$ & $1.46 \pm 0.06$ \\
\hline C20:3 n-9 & $24.18 \pm 7.49$ & $21.95 \pm 2.35$ & $0.95 \pm 0.55^{*}$ & $1.26 \pm 0.88^{*}$ & $27.58 \pm 5.42$ & $67.52 \pm 7.16^{*}$ \\
\hline C20:3 n-6 & $19.38 \pm 2.72$ & $25.77 \pm 3.04$ & $3.94 \pm 0.80 *$ & $5.67 \pm 1.93^{*}$ & $90.98 \pm 8.43^{*}$ & $19.58 \pm 1.08$ \\
\hline C20:4 n-6 & $85.6 \pm 11.5$ & $104.0 \pm 11.4$ & $23.9 \pm 1.6^{*}$ & $107.4 \pm 8.9$ & $221.4 \pm 25.3^{*}$ & $102.2 \pm 5.9$ \\
\hline C20:5 n-3 & $4.38 \pm 0.7$ & $5.07 \pm 0.4$ & $201.9 \pm 16.6^{*}$ & $54.9 \pm 8.1 *$ & $15.5 \pm 0.8^{*}$ & $6.1 \pm 0.4$ \\
\hline $\mathrm{C} 22: 0$ & $4.19 \pm 0.95$ & $4.68 \pm 0.21$ & $4.41 \pm 0.44$ & $7.06 \pm 1.51$ & $5.44 \pm 0.58$ & $4.32 \pm 0.21$ \\
\hline C22:1 n-9 & $1.03 \pm 0.37$ & $1.50 \pm 0.08$ & $1.32 \pm 0.10$ & $0.43 \pm 0.43$ & $0.00 \pm 0.00 *$ & $0.38 \pm 0.38$ \\
\hline $\mathrm{C} 22: 4 \mathrm{n}-6$ & $3.86 \pm 1.44$ & $2.41 \pm 0.30$ & $0.00 \pm 0.00 *$ & $1.90 \pm 1.00$ & $9.53 \pm 1.13^{*}$ & $2.29 \pm 0.19$ \\
\hline $\mathrm{C} 22: 5 \mathrm{n}-3$ & $4.13 \pm 0.94$ & $3.68 \pm 0.37$ & $58.34 \pm 5.65^{*}$ & $29.95 \pm 9.42 *$ & $13.77 \pm 0.51^{*}$ & $3.53 \pm 0.20$ \\
\hline C22:6 n-3 & $117.9 \pm 19.4$ & $100.9 \pm 7.6$ & $103.0 \pm 15.4$ & $460.4 \pm 64.8^{*}$ & $169.5 \pm 13.0$ & $89.6 \pm 5.1$ \\
\hline $\mathrm{C} 24: 0$ & $2.79 \pm 0.76$ & $2.86 \pm 0.34$ & $3.48 \pm 0.36$ & $3.33 \pm 0.64$ & $3.31 \pm 0.34$ & $2.95 \pm 0.35$ \\
\hline C24:1 n-9 & $5.47 \pm 1.06$ & $6.59 \pm 0.70$ & $5.00 \pm 0.71$ & $5.15 \pm 0.84$ & $8.73 \pm 0.96$ & $5.85 \pm 0.30$ \\
\hline \multicolumn{7}{|c|}{ ob/ob ( $\mu \mathrm{g} / \mathrm{g}$ body weight) } \\
\hline C12:0 & $4.52 \pm 0.35$ & $3.99 \pm 0.47^{*}$ & $1.67 \pm 0.60$ & $2.71 \pm 0.95$ & $4.02 \pm 0.36$ & $5.08 \pm 0.23$ \\
\hline C14:0 & $169.3 \pm 7.2$ & $159.3 \pm 22.7$ & $84.0 \pm 15.3^{*}$ & $90.9 \pm 16.1^{*}$ & $128.4 \pm 4.2^{*}$ & $191.9 \pm 9.0$ \\
\hline C14:1 n-5 & $7.72 \pm 0.70$ & $5.75 \pm 1.27$ & $1.52 \pm 0.98^{*}$ & $1.97 \pm 0.69 *$ & $3.47 \pm 0.12 *$ & $9.47 \pm 0.84$ \\
\hline $\mathrm{C} 16: 0$ & $6397 \pm 198$ & $5797 \pm 553$ & $3328 \pm 544 *$ & $3488 \pm 554^{*}$ & $5932 \pm 289$ & $6553 \pm 477$ \\
\hline C16:1 n-7 & $1673 \pm 153$ & $1458 \pm 231$ & $753 \pm 141 *$ & $912 \pm 136^{*}$ & $1563 \pm 60$ & $2375 \pm 155^{*}$ \\
\hline C18:0 & $587.6 \pm 28.2$ & $490.5 \pm 13.3^{*}$ & $374.7 \pm 36.4^{*}$ & $363.2 \pm 62.0^{*}$ & $416.6 \pm 18.1^{*}$ & $464.2 \pm 29.1 *$ \\
\hline C18:1 n-9 & $12964 \pm 214$ & $13207 \pm 1229$ & $7661 \pm 1563 *$ & $6551 \pm 1137^{*}$ & $11014 \pm 656^{*}$ & $15045 \pm 639 *$ \\
\hline C18:2 n-6 & $1260.3 \pm 242.7$ & $1308.2 \pm 22.3$ & $921.5 \pm 87.7$ & $1033.6 \pm 146.4$ & $1113.5 \pm 93.1$ & $986.2 \pm 106.9$ \\
\hline C18:3 n-6 & $12.83 \pm 2.18$ & $11.67 \pm 0.92$ & $4.21 \pm 0.81 *$ & $6.53 \pm 1.01 *$ & $10.14 \pm 1.02$ & $9.77 \pm 1.86$ \\
\hline C18:3 n-3 & $45.6 \pm 9.7$ & $51.4 \pm 2.8$ & $53.0 \pm 4.8$ & $79.9 \pm 17.3$ & $35.1 \pm 3.6$ & $24.5 \pm 2.2$ \\
\hline $\mathrm{C} 20: 0$ & $7.48 \pm 0.56$ & $6.34 \pm 0.52$ & $5.88 \pm 0.91$ & $8.51 \pm 3.02$ & $6.47 \pm 0.73$ & $13.21 \pm 1.24$ \\
\hline C20:1 n-9 & $386.1 \pm 22.1$ & $412.3 \pm 60.0$ & $177.9 \pm 44.9 *$ & $148.1 \pm 26.1^{*}$ & $286.9 \pm 23.4^{*}$ & $535.6 \pm 13.1^{*}$ \\
\hline C20:2 n-6 & $31.4 \pm 6.2$ & $37.6 \pm 0.6$ & $20.0 \pm 3.0$ & $19.9 \pm 2.4$ & $21.8 \pm 2.9$ & $24.4 \pm 3.5$ \\
\hline $\mathrm{C} 20: 3 \mathrm{n}-9$ & $37.61 \pm 4.07$ & $36.39 \pm 2.85$ & $13.71 \pm 1.89 *$ & $10.19 \pm 0.79 *$ & $26.86 \pm 3.19$ & $59.54 \pm 8.41$ \\
\hline$C 20: 3 n-6$ & $85.2 \pm 10.8$ & $91.2 \pm 2.1$ & $41.5 \pm 5.2^{*}$ & $38.5 \pm 3.7^{*}$ & $82.4 \pm 5.7$ & $70.8 \pm 6.1$ \\
\hline C20:4 n-6 & $134.6 \pm 41.8$ & $164.4 \pm 2.6$ & $76.2 \pm 9.2$ & $152.3 \pm 18.1$ & $140.1 \pm 8.6$ & $146.7 \pm 14.2$ \\
\hline C20:5 n-3 & $54.6 \pm 6.0$ & $57.9 \pm 1.3$ & $387.8 \pm 13.8 *$ & $382.1 \pm 70.6^{*}$ & $65.4 \pm 2.1$ & $45.7 \pm 4.1$ \\
\hline $\mathrm{C} 22: 0$ & $4.61 \pm 0.48$ & $2.29 \pm 0.80 *$ & $3.23 \pm 0.23 *$ & $3.09 \pm 1.15$ & $1.50 \pm 0.87^{*}$ & $2.44 \pm 0.88$ \\
\hline $\mathrm{C} 22: 1 \mathrm{n}-9$ & $9.7 \pm 0.5$ & $7.5 \pm 0.5^{*}$ & $1.4 \pm 0.8^{*}$ & $0.6 \pm 0.6^{*}$ & $5.6 \pm 0.7^{*}$ & $13.0 \pm 0.5^{*}$ \\
\hline C22:4 n-6 & $11.3 \pm 1.3$ & $12.3 \pm 0.7$ & $3.8 \pm 0.6^{*}$ & $11.0 \pm 1.2$ & $5.4 \pm 1.1^{*}$ & $10.3 \pm 1.7$ \\
\hline$C 22: 5 n-3$ & $64.3 \pm 9.4$ & $74.2 \pm 3.4$ & $266.4 \pm 28.4 *$ & $221.3 \pm 33.6^{*}$ & $38.5 \pm 3.0^{*}$ & $38.1 \pm 3.7^{*}$ \\
\hline $\mathrm{C} 22: 6 \mathrm{n}-3$ & $350.2 \pm 34.3$ & $378.9 \pm 8.6$ & $317.4 \pm 33.3$ & $1130.7 \pm 168.8^{*}$ & $244.7 \pm 11.8^{*}$ & $185.9 \pm 20.9 *$ \\
\hline $\mathrm{C} 24: 0$ & $2.4 \pm 0.8$ & $1.4 \pm 0.8$ & $2.4 \pm 0.8$ & $2.2 \pm 0.8$ & $2.0 \pm 0.7$ & $0.6 \pm 0.6$ \\
\hline C24:1 n-9 & $12.0 \pm 0.8$ & $11.3 \pm 0.5$ & $9.6 \pm 0.6$ & $10.2 \pm 1.1$ & $9.9 \pm 0.4$ & $11.3 \pm 0.7$ \\
\hline
\end{tabular}

NOTE. Diets are as follows: 1, a high-carbohydrate fat-free diet; 2, a high-carbohydrate diet with 15\% triolein (C18:1 n-9); 3, 5\% EPA ethyl ester (C20:5 n-3) plus $15 \%$ triolein (C18:1 n-9); 4, 20\% tuna fish oil; 5, 0.125\% fenofibrate, a PPAR $\alpha$ agonist; 6, 0.05\% pioglitazone, a PPAR $\gamma$ agonist. Each value is mean \pm SE.

* Significance vs. control at $P<.05$ by Student's $t$ test.

cose-lipid metabolism (Fig. 6). It has been suggested that $\operatorname{PPAR} \alpha$ agonists reduce insulin resistance, ${ }^{29,30}$ and, in this study, fenofibrate did ameliorate hyperinsulinemia and hyperglycemia in the oblob mice, although to a lesser degree than the established insulin sensitizer pioglitazone. Intriguingly, PUFA also reduced serum glucose and insu- lin levels nearly to the same level as fenofibrate. By Northern blot analysis, the expression of insulin receptor substrate (IRS)-2, a key molecule in insulin signaling, in both liver and adipose tissue of $o b / o b$ mice were shown to be lowered, but its expression was slightly restored by the PUFA administration (Fig. 3). 


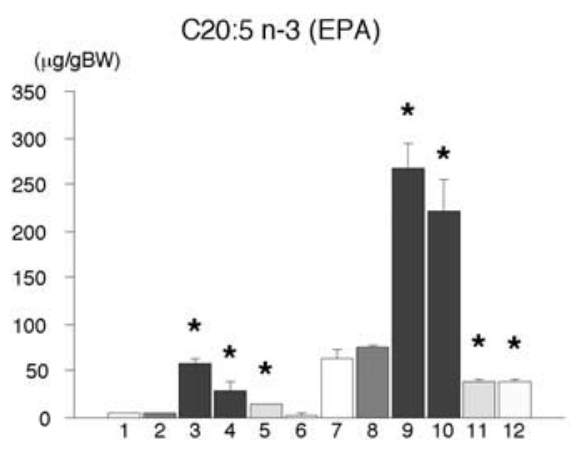

n-3
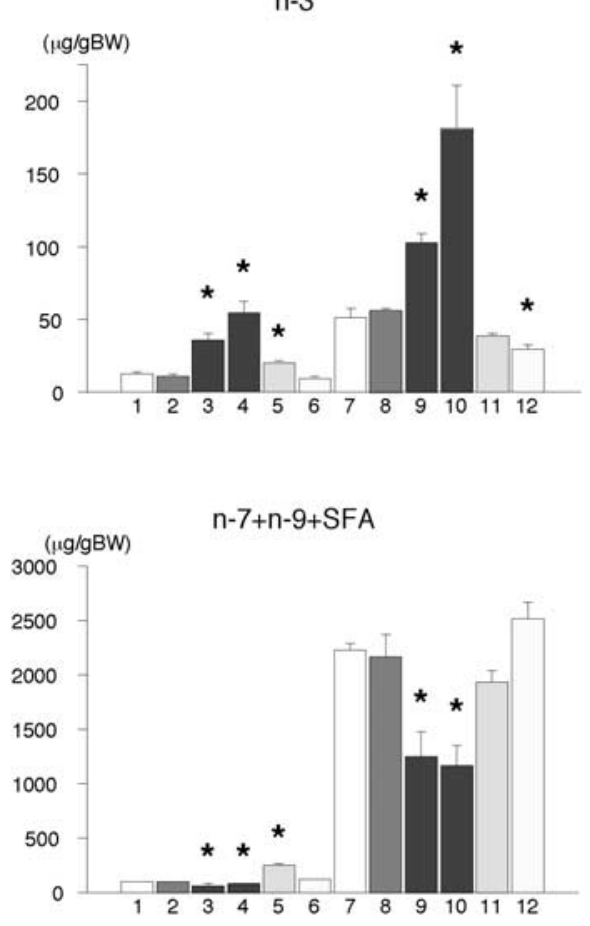

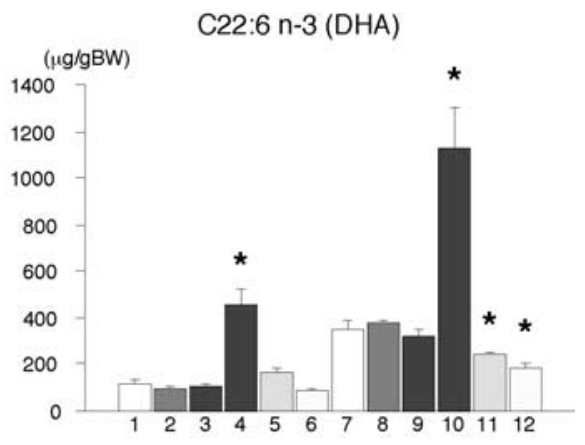

n-6

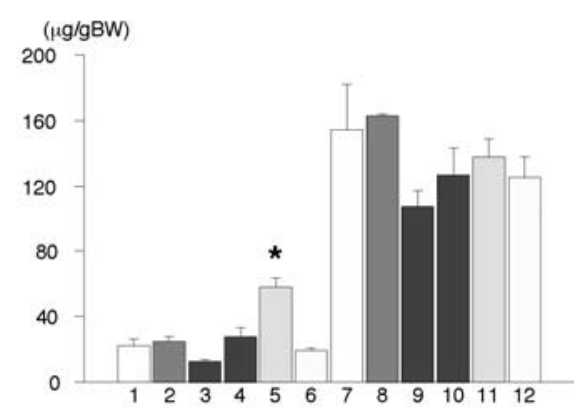

Fig. 5. Effects of PUFA on fatty acid composition in the liver of wildtype and ob/ob mice. The composition of fatty acids in liver was measured by gas chromatography. Based on the data shown in Table 2, $\mathrm{n}-3, \mathrm{n}-6$, or $\mathrm{n}-7 / \mathrm{n}-9 /$ saturated fatty acids (SFA) content is calculated and illustrated. Diets are as follows: lanes 1 and 7, a high-carbohydrate, fat-free diet; lanes $\mathbf{2}$ and $\mathbf{8}$, a highcarbohydrate diet with $15 \%$ triolein (C18:1 n-9); lanes 3 and 9, 5\% EPA ethyl ester (C20:5 n-3) plus 15\% triolein (C18:1 n-9); lanes 4 and 10, 20\% tuna fish oil; lanes 5 and 11, $0.125 \%$ fenofibrate, a PPAR $\alpha$ agonist; and lanes $\mathbf{6}$ and 12, 0.05\% pioglitazone, a PPAR $\gamma$ agonist. Lanes $\mathbf{1}$ to $\mathbf{6}$ are data from wild-type mice, and lanes $\mathbf{7}$ to $\mathbf{1 2}$ are from $o b / o b$ mice ( $n=4$ for each group). Bars $=\mathrm{SE}$. ${ }^{*}$ Denotes significance vs. control (lane $\mathbf{1}$ or $\mathbf{7}$ ) at $P<.05$ (Student's $t$ test). Series of experiments were performed twice for the same number of animals, and the data from a representative experiment are shown.

\section{Discussion}

The current study clearly demonstrates that PUFAs reduce mature SREBP-1 and ameliorate hepatic steatosis in $o b / o b$ mice. Based on our previous findings that PUFAs suppress SREBP- $1{ }^{10}$ and that SREBP-1-null $o b / o b$ mice have less triglycerides in liver, ${ }^{5}$ we hypothesized that PUFA would decrease hepatic triglyceride storage through the reduction of SREBP-1. Our results provide a strong clinical implication that PUFAs are potentially useful for the treatment of hepatic steatosis. In addition, we provided further evidence that SREBP-1 regulates the storage of triglycerides in liver. In this regard, we speculate that the reduction of hepatic lipogenesis by PUFA resulted in a decrease in triglyceride storage. Two lines of evidence indicate decreased lipogenesis in PUFA-fed mouse livers: a decrease in lipogenic enzymes mRNA levels as shown by Northern blot analysis (Fig. 2) and the hepatic fatty acid composition (Table 2, Fig. 5), demon- strating that PUFA administration decreased fatty acids such as oleate (C18:1 n-9), palmitate (C16:0), and palmitoleate $(\mathrm{C} 16: 1 \mathrm{n}-7)$ that can be endogenously synthesized more profoundly than fatty acids such as linoleate (C18:2 n-6) that cannot be biosynthesized de novo.

In the present study, we show that EPA administration decreased hepatic triglyceride content in oblob mice, whereas it did not in a transgenic mouse model, which forcibly expressed a mature form of SREBP-1 protein in the liver (TgSREBP1). These findings indicate that the effect of EPA on the improvement of hepatic steatosis is mainly mediated by SREBP-1 reduction. In contrast, tuna oil, rich in DHA, was also effective in the $\mathrm{Tg}$ SREBP1 mice. These data indicate that tuna oil may have additional positive effects beyond the suppression of SREBP-1. The difference between them might be derived from differences in composition and action of EPA versus DHA. In fact, although EPA can be converted to DHA 
Fig. 6. PUFAs improve hyperglycemia and hyperinsulinemia of $o b / o b$ mice. Plasma glucose, insulin, and free fatty acids (FFA) of wild-type (WT) and ob/ob (OB) mice ( $\mathrm{n}=4$ for each group) are shown. Diets are as follows: lane 1, a high-carbohydrate, fat-free diet; lane 2, 15\% triolein (C18:1 n-9); lane 3, 5\% EPA ethyl ester (C20:5 $n-3)$ plus $15 \%$ triolein (C18:1 n-9); lane 4, 20\% tuna fish oil; lane 5, 0.125\% fenofibrate, a PPAR $\alpha$ agonist; lane $\mathbf{6}$, $0.05 \%$ pioglitazone, a PPAR $\gamma$ agonist. Bars $=\mathrm{SE}$. ${ }^{*}$ Denotes significance vs. control (lane 1) at $P<$ .05 (Student's $t$ test). Series of experiments were performed twice for the same number of animals, and the data from a representative experiment are shown.
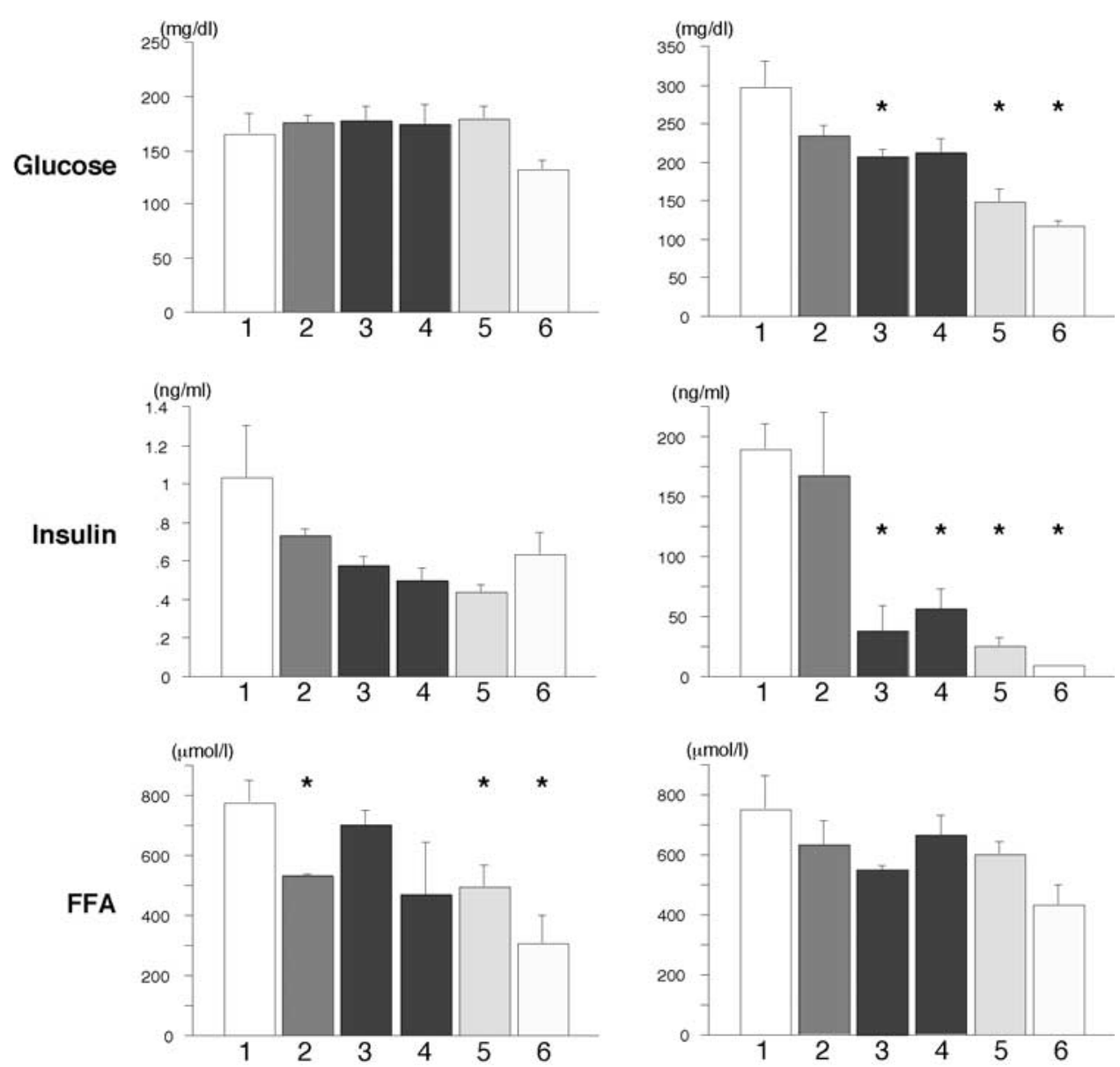

endogenously with elongase and $\Delta 6$-desaturase via the Sprecher pathway, ${ }^{31}$ the hepatic content of DHA in mice administered EPA was not elevated, as shown in Fig. 5, presumably because of the suppression of $\Delta 6$-desaturase expression by PUFA. ${ }^{24,25}$ Although EPA and DHA are considered equally effective as suppressors of SREBP- $1,{ }^{10}$

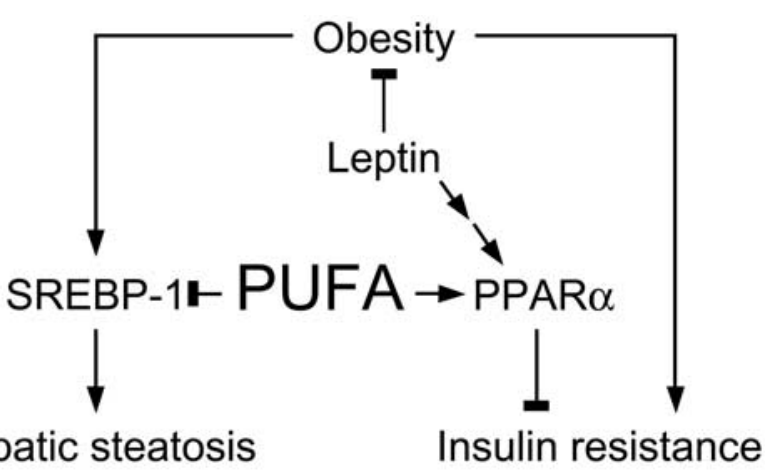

Fig. 7. Schematic representation of PUFA effects on obesity. PUFAs suppress SREBP-1 and activate PPAR $\alpha$, thereby preventing excess triglyceride accumulation and ameliorating obesity-associated symptoms, including hepatic steatosis and insulin resistance. the mechanisms by which PUFAs suppress triglyceride synthesis are known to be divergent, ${ }^{32}$ and they might have different potency for the SREBP-1-independent pathways. It is also possible that some unknown substance in tuna oil could be responsible for the SREBP-1-independent action.

We showed that PUFA not only ameliorated hepatic steatosis but also attenuated insulin resistance in ob/ob mice. Although the precise mechanisms are currently unknown, we are speculating that this effect of PUFA was mediated at least partially by the PPAR $\alpha$ receptor because PUFAs are well known PPAR $\alpha$ ligands, ${ }^{27}$ and a PPAR $\alpha$ agonist, fenofibrate, was also demonstrated to improve insulin sensitivity in ob/ob mice as shown in Fig. 6. We presume that this effect of PUFA is not mediated by SREBP-1 because it was previously shown that the disruption of SREBP-1 in $o b / o b$ mice did not influence their insulin resistance. ${ }^{5}$ However, it should be noted that EPA was equally competent in improving the hyperinsulinemia of $o b / o b$ mice, whereas EPA was much weaker in $\operatorname{PPAR} \alpha$ activation as estimated by Northern blot analysis 
for PPAR $\alpha$ target genes. It is tempting to speculate that there could also be other mechanisms for insulin sensitization by PUFA than the PPAR $\alpha$ pathway; for instance, it is possible that altered phospholipid composition and thereby membrane fluidity might be involved. ${ }^{33,34}$

We also showed that PUFAs significantly $(P<.05)$ reduce hepatic cholesterol content in wild-type mice (Fig. $4 \mathrm{~A})$. This is in accordance with previous reports ${ }^{35,36}$ that fish oil feeding decreased hepatic cholesterol content in rodents. The mechanism by which this occurs is currently unknown, but it was documented that EPA has an inhibitory effect on hepatic cholesterol biosynthesis and an enhancing effect on hepatic biliary secretion. ${ }^{37}$ Although the mRNA expression levels of cholesterol biosynthetic genes were not shown to be lowered by PUFA in Northern blotting (Fig. 2), these analyses do not account for possible posttranscriptional effects.

As we summarized in Fig. 7, PUFAs down-regulate SREBP-1 and, thereby, triglyceride synthesis and at the same time activate the PPAR $\alpha$ receptor, leading to the increased $\beta$-oxidation of fatty acids. Hence, PUFA can shift the energy balance from storage to consumption. The antilipogenic action of PUFA through SREBP-1 suppression has been proven to be independent of the $\operatorname{PPAR} \alpha$ pathway by previous studies using $\operatorname{PPAR} \alpha$ knockout mice. ${ }^{28}$

From a therapeutic point of view, it was notable that PUFA also decreased plasma ALT levels. This means that PUFAs attenuate the liver injury resulting from excess triglyceride deposition. Although the precise pathophysiology as to how hepatic steatosis leads to steatohepatitis and even to cirrhosis remains unclear, liver disease might be a major contributor to overall obesity-related morbidity and mortality. ${ }^{38}$ Our data suggest that PUFA might be of clinical use to prevent the liver dysfunction associated with over nutrition.

In conclusion, we demonstrate that PUFAs ameliorate hepatic steatosis through the suppression of SREBP-1 in ob/ob mice. Furthermore, PUFAs were suggested to be presumably of clinical value as a therapeutic drug for insulin resistance.

Acknowledgment: The authors thank Takashi Yano, Hiroyuki Kawano, Masaaki Soma, and Toyonori Kato for continuous support of the project; Alyssa H. Hasty for critical reading of the manuscript; and Kumiko Kitaoka for assistance with the experiments.

\section{References}

1. Brown MS, Goldstein JL. The SREBP pathway: regulation of cholesterol metabolism by proteolysis of a membrane-bound transcription factor. Cell 1997;89:331-340.

2. Shimano H. Sterol regulatory element-binding proteins (SREBPs): transcriptional regulators of lipid synthetic genes. Prog Lipid Res 2001;40:439-452.
3. Horton JD, Goldstein JL, Brown MS. SREBPs: activators of the complete program of cholesterol and fatty acid synthesis in the liver. J Clin Invest 2002;109:1125-1131.

4. Shimano H, Horton JD, Shimomura I, Hammer RE, Brown MS, Goldstein JL. Isoform 1c of sterol regulatory element binding protein is less active than isoform 1a in livers of transgenic mice and in cultured cells. J Clin Invest 1997;99:846-854.

5. Yahagi N, Shimano H, Hasty AH, Matsuzaka T, Ide T, Yoshikawa T, Amemiya-Kudo $\mathrm{M}$, et al. Absence of sterol regulatory element-binding protein-1 (SREBP-1) ameliorates fatty livers but not obesity or insulin resistance in Lep(ob)/Lep(ob) mice. J Biol Chem 2002;277:19353-19357.

6. Bray GA, York DA. Hypothalamic and genetic obesity in experimental animals: an autonomic and endocrine hypothesis. Physiol Rev 1979;59: 719-809.

7. Clandinin MT, Cheema S, Pehowich D, Field CJ. Effect of polyunsaturated fatty acids in obese mice. Lipids 1996;31(Suppl):S13-S22.

8. Shimomura I, Bashmakov Y, Horton JD. Increased levels of nuclear SREBP-1c associated with fatty livers in two mouse models of diabetes mellitus. J Biol Chem 1999;274:30028-30032.

9. Clarke SD, Jump DB. Dietary polyunsaturated fatty acid regulation of gene transcription. Annu Rev Nutr 1994;14:83-98.

10. Yahagi N, Shimano H, Hasty AH, Amemiya-Kudo M, Okazaki H, Tamura Y, lizuka Y, et al. A crucial role of sterol regulatory elementbinding protein-1 in the regulation of lipogenic gene expression by polyunsaturated fatty acids. J Biol Chem 1999;274:35840-35844.

11. Xu J, Nakamura MT, Cho HP, Clarke SD. Sterol regulatory element binding protein-1 expression is suppressed by dietary polyunsaturated fatty acids. A mechanism for the coordinate suppression of lipogenic genes by polyunsaturated fats. J Biol Chem 1999;274:23577-23583.

12. Kim HJ, Takahashi M, Ezaki O. Fish oil feeding decreases mature sterol regulatory element-binding protein 1 (SREBP-1) by down-regulation of SREBP-1c mRNA in mouse liver. A possible mechanism for down-regulation of lipogenic enzyme mRNAs. J Biol Chem 1999;274:25892-25898.

13. Mater MK, Thelen AP, Pan DA, Jump DB. Sterol response elementbinding protein 1c (SREBP1c) is involved in the polyunsaturated fatty acid suppression of hepatic S14 gene transcription. J Biol Chem 1999;274: 32725-32732.

14. Yoshikawa T, Shimano H, Yahagi N, Ide T, Amemiya-Kudo M, Matsuzaka T, Nakakuki M, et al. Polyunsaturated fatty acids suppress sterol regulatory element-binding protein $1 \mathrm{c}$ promoter activity by inhibition of liver X receptor (LXR) binding to LXR response elements. J Biol Chem 2002;277:1705-1711.

15. Xu J, Teran-Garcia M, Park JH, Nakamura MT, Clarke SD. Polyunsaturated fatty acids suppress hepatic sterol regulatory element- binding protein-1 expression by accelerating transcript decay. J Biol Chem 2001;276: 9800-9807.

16. Yokode M, Hammer RE, Ishibashi S, Brown MS, Goldstein JL. Dietinduced hypercholesterolemia in mice: prevention by overexpression of LDL receptors. Science 1990;250:1273-1275.

17. Shimano H, Horton JD, Hammer RE, Shimomura I, Brown MS, Goldstein JL. Overproduction of cholesterol and fatty acids causes massive liver enlargement in transgenic mice expressing truncated SREBP-1a. J Clin Invest 1996;98:1575-1584.

18. Shimomura I, Shimano H, Horton JD, Goldstein JL, Brown MS. Differential expression of exons $1 \mathrm{a}$ and $1 \mathrm{c}$ in mRNA for sterol regulatory element binding protein-1 in human and mouse organs and cultured cells. J Clin Invest 1997;99:838-845.

19. Sheng Z, Otani H, Brown MS, Goldstein JL. Independent regulation of sterol regulatory element-binding proteins 1 and 2 in hamster liver. Proc Natl Acad Sci U S A 1995;92:935-938.

20. Shimano H, Shimomura I, Hammer RE, Herz J, Goldstein JL, Brown MS, Horton JD. Elevated levels of SREBP-2 and cholesterol synthesis in livers of mice homozygous for a targeted disruption of the SREBP-1 gene. J Clin Invest 1997;100:2115-2124.

21. Sattler W, Puhl H, Hayn M, Kostner GM, Esterbauer H. Determination of fatty acids in the main lipoprotein classes by capillary gas chromatogra- 
phy: BF3/methanol transesterification of lyophilized samples instead of Folch extraction gives higher yields. Anal Biochem 1991;198:184-190.

22. Folch J, Lees M, Sloane Stanley GH. A simple method for the isolation and purification of total lipides from animal tissues. J Biol Chem 1957;226: 497-509.

23. Cho HP, Nakamura M, Clarke SD. Cloning, expression, and fatty acid regulation of the human $\Delta-5$ desaturase. J Biol Chem 1999;274:3733537339.

24. Cho HP, Nakamura MT, Clarke SD. Cloning, expression, and nutritional regulation of the mammalian $\Delta-6$ desaturase. J Biol Chem 1999;274:471477.

25. Matsuzaka T, Shimano H, Yahagi N, Amemiya-Kudo M, Yoshikawa T, Hasty AH, Tamura Y, et al. Dual regulation of mouse $\Delta(5)$ - and $\Delta(6)$ desaturase gene expression by SREBP-1 and PPAR $\alpha$. J Lipid Res 2002;43: 107-114.

26. Gottlicher M, Widmark E, Li Q, Gustafsson JA. Fatty acids activate a chimera of the clofibric acid-activated receptor and the glucocorticoid receptor. Proc Natl Acad Sci U S A 1992;89:4653-4657.

27. Forman BM, Chen J, Evans RM. Hypolipidemic drugs, polyunsaturated fatty acids, and eicosanoids are ligands for peroxisome proliferator-activated receptors alpha and delta. Proc Natl Acad Sci U S A 1997;94:43124317.

28. Ren B, Thelen AP, Peters JM, Gonzalez FJ, Jump DB. Polyunsaturated fatty acid suppression of hepatic fatty acid synthase and S14 gene expression does not require peroxisome proliferator-activated receptor $\alpha$. J Biol Chem 1997;272:26827-26832.

29. Matsui H, Okumura K, Kawakami K, Hibino M, Toki Y, Ito T. Improved insulin sensitivity by bezafibrate in rats: relationship to fatty acid composition of skeletal-muscle triglycerides. Diabetes 1997;46:348-353.
30. Guerre-Millo M, Gervois P, Raspe E, Madsen L, Poulain P, Derudas B, Herbert JM, et al. Peroxisome proliferator-activated receptor $\alpha$ activators improve insulin sensitivity and reduce adiposity. J Biol Chem 2000;275: 16638-16642.

31. Voss A, Reinhart M, Sankarappa S, Sprecher H. The metabolism of 7,10,13,16,19-docosapentaenoic acid to 4,7,10,13,16,19-docosahexaenoic acid in rat liver is independent of a 4-desaturase. J Biol Chem 1991; 266:19995-20000.

32. Jump DB. Dietary polyunsaturated fatty acids and regulation of gene transcription. Curr Opin Lipidol 2002;13:155-164.

33. Storlien LH, Kraegen EW, Chisholm DJ, Ford GL, Bruce DG, Pascoe WS. Fish oil prevents insulin resistance induced by high-fat feeding in rats. Science 1987;237:885-888.

34. Field CJ, Ryan EA, Thomson AB, Clandinin MT. Diet fat composition alters membrane phospholipid composition, insulin binding, and glucose metabolism in adipocytes from control and diabetic animals. J Biol Chem 1990;265:11143-11150.

35. Takahashi M, Tsuboyama-Kasaoka N, Nakatani T, Ishii M, Tsutsumi S, Aburatani H, Ezaki O. Fish oil feeding alters liver gene expressions to defend against PPARalpha activation and ROS production. Am J Physiol Gastrointest Liver Physiol 2002;282:G338-G348.

36. Surette ME, Whelan J, Lu GP, Broughton KS, Kinsella JE. Dependence on dietary cholesterol for $\mathrm{n}-3$ polyunsaturated fatty acid-induced changes in plasma cholesterol in the Syrian hamster. J Lipid Res 1992;33:263-271.

37. Mizuguchi K, Yano T, Tanaka Y, Ishibashi M, Masada A, Mizota M, Fukutake K, et al. Mechanism of the lipid-lowering effect of ethyl all-cis5,8,11,14,17-icosapentaenoate. Eur J Pharmacol 1993;231:121-127.

38. Angulo P. Nonalcoholic fatty liver disease. N Engl J Med 2002;346:12211231. 